\title{
A NECESSÁRIA TRANSIÇÃO PLANETÁRIA: (IN) CONVENIENTES DO COVID-19 PARA VIABILIZAR A BENFAZEJA COLHEITA FUTURA NO BRASIL E NA COMUNIDADE INTERNACIONAL DE ESTADOS
}

\section{THE NECESSARY PLANET TRANSITION: THE (IN)CONVENIENCE OF THE COVID-19 TO MAKE IT FEASIBLE THE GOOD FUTURE HARVEST IN BRAZIL AND IN THE AT INTERNATIONAL COMMUNITY OF STATES}

EVERTON DAS NEVES GONÇALVES Professor Titular da UFSC. Doutor em Direito Econômico (UFMG/MG); Doctor en Derecho Internacional Económico por la Universidad de Buenos Aires (UBA/ Bs. As.) Argentina; Mestre em Direito (UFSC/SC); Especialista em Comércio Exterior e Integração Econômica no MERCOSUL (FURG/RS); Especialista em Administração Universitária (FURG/RS); Professor credenciado no Programa de Pós-Graduação em Direito da Universidade Federal de Santa Catarina (PPGD/UFSC); Coordenador do Centro de Estudos Jurídico-Econômicos e de Gestão para o Desenvolvimento (CEJEGD). E-mail: evertong@vetorial.net

\section{RESUMO}

Objetivo: O trabalho registra as primeiras impressões, em especial, no Brasil, em março de 2020, sobre origem e avanço do COVID-19 a partir de uma situação anômala de quarentena física. Como objetivo geral, o estudo investiga a visão espiritualista da análise econômica do Direito como instrumental para implementar alteridade nas relações sociais.

Metodologia: Trata-se de pesquisa qualitativa, de método dedutivo e com recurso à análise bibliográfica e documental; tem como marco teórico, autores 
neoinstitucionalistas como Douglas North e Joseph Schumpeter e espíritas como Francisco Candido Xavier e Divaldo Pereira Franco.

Resultados: Conclui-se que o COVID-19 propicia a oportunidade para a difusão de visão político-econômico-jurídica, voltada para a alteridade e a felicidade, a necessidade de mudança na forma de agir individual e coletiva para que seja possível a felicidade. O COVID-19 vem como mais um instrumento de "reorganização" da humanidade, ainda que o custo de vidas seja tão alto do ponto de vista existencial. O ceifar da morte ainda nos deixa perplexos; porém, do ponto de vista da essência humana, grandes aprendizados podem ser introjetados em nossa experiência de vida.

Contribuições: O trabalho registra a origem e avanço do COVID-19, destacando a necessidade de mudança no agir individual e coletivo, possibilitando a felicidade. Especificamente, objetiva alertar para a necessidade de comportamento econômicojurídico, visando o bem econômico social através da "autodestruição renovadora eficiente-econômico-social" (ADRECOS).

Palavras-chave: Direito e Economia; Direito e felicidade; análise econômica do Direito e o COVID-19.

\section{ABSTRACT}

Objective: The paper records the first impressions, especially in Brazil, in March 2020, about the origin and advance of COVID-19 from an anomalous physical quarantine situation. As a general objective, the study investigates the spiritualist view of economic analysis of Law as instrumental to implement otherness in social relations.

Methodology: This is a qualitative research, using a deductive method and bibliographic and documentary analysis; has as its theoretical framework, neoinstitutionalist authors such as Douglas North and Joseph Schumpeter and spiritualist such as Francisco Cândido Xavier and Divaldo Pereira Franco.

Results: It is concluded that COVID-19 provides the opportunity for the diffusion of a political-economic-legal view, focused on otherness and happiness, the need to change the way of acting individually and collectively, so that happiness is possible. COVID-19 comes as another instrument for the "reorganization" of humanity, even though the cost of living is so high from an existential point of view. The reaping of death still perplexes us; however, from the point of view of human essence, great learnings can be introjected into our life experience.

Contributions: The work records the origin and progress of COVID-19, highlighting the need for change in individual and collective action, enabling happiness. 
Specifically, it aims to alert to the need for economic-legal behavior, aiming at the social economic good through the "efficient-economic-social renovating selfdestruction" (ADRECOS).

Keywords: Law and Economics; Law and happiness; economic analysis of Law and COVID-19.

\section{INTRODUÇÃO}

O trabalho registra as primeiras impressões, em especial, no Brasil, em março de 2020, sobre a origem e o avanço do COVID-19 destacando, a partir de uma situação anômala de quarentena física, a necessidade de mudança na forma de agir individual e coletiva para que seja possível a felicidade. Como objetivo geral, destaca a necessidade de novel visão espiritualista da Análise Econômica do Direito como instrumental acadêmico-político-jurídico para implementar alteridade nas relações sociais. Tem como marco teórico autores neo-institucionalistas, como Douglas North e Joseph Schumpeter e espíritas como Francisco Candido Xavier e Divaldo Pereira Franco. Especificamente, objetiva alertar para a necessidade de comportamento econômico-jurídico visando o bem econômico social, próprio do Princípio da Eficiência Econômico Social - PEES, através da "autodestruição renovadora eficiente-econômico-social" (ADRECOS). Trata-se de pesquisa qualitativa, tem método de abordagem dedutivo e com recurso à análise bibliográfica e documental.

Para serem atingidos os objetivos, após introdução, desenvolve-se o conteúdo de forma a, gradualmente, apresentarem-se dados vivenciados no início da expansão do COVID-19, mormente no Brasil; evidenciarem-se outras exemplificativas tragédias humanas e proporem-se questões para suscitar a possibilidade do uso do "ferramental" jurídico-econômico das Escolas da Law and Economics ou da Análise econômica do Direito segundo a visão espiritualista, para que se conquiste harmonia econômico-político-social e a coexistência para a felicidade. O COVID-19, então, passa a ser visto como efetiva oportunidade para a humanização das pessoas, ainda que com altíssimo custo de transação, 
destacando-se visões materialista e espiritualista para analisar o momento de quarentena vivenciado no Brasil. Pugna-se, finalmente, pela difusão do trabalho, na Universidade, para difusão da ideia de felicidade incluída na ação educativa pelo uso dos ferramentais jurídico-econômicos.Neste sentido, conclui-se que o COVID-19 propicia a necessária oportunidade para a difusão de visão político-econômicojurídica voltada para a alteridade e felicidade.

Estamos a 20 de março de 2020, Dia da Felicidade, que se comemora desde 1972, quando, em um Estado chamado Butão, passou-se a medir o FIB (Felicidade Interna Bruta) para além do PIB (Produto Interno Bruto). De outro lado, desde 31 de dezembro de 2019, quando se descobriu, em Wuhan, República Popular da China, o COVID-19, um vírus mortal que teria surgido a partir dos "mercados molhados de animais". Naquela Cidade ${ }^{1}$, o Planeta Terra e sua humanidade já não seriam mais os mesmos.

\subsection{DESENVOLVIMENTO}

Em dois meses e vinte dias, morreram mais de 11.400 pessoas em um universo de 275.000 contaminações (números oficiais que, provavelmente podem ser majorados se considerada a subnotificação de casos). Especialmente, no Brasil, a partir do dia 16 de março de 2020, as diversas autoridades, mormente, do Poder Executivo (Federal, Estadual e Municipal), iniciaram a exarar medidas normativas progressivas e rapidamente mais restritivas de liberdade de locomoção da população civil. Lockdown nas cidades, barreiras físicas, e até impedimento de acesso às cidades e aos Estados foram intentadas para conter o avanço do COVID19. Já há, em solo pátrio, 978 casos confirmados de contaminação e 11 mortes; números que, provavelmente, estão aquém da realidade em vista de que o País não tem kits de testagem suficientes para averiguação de casos.

\footnotetext{
1 Ver, para além de outros especialistas, trabalhos do Doutor Peter J. Li Professor Associado na Universidade de Houston-Downtown e especialista em políticas públicas chinesas, porta-voz da Human Society International (HSI). Suas pesquisas tratam das políticas de bem-estar animal na China e do movimento de proteção animal naquele País.
} 
Nas suas casas, isoladas em quarentena, as pessoas passaram a acompanhar a terrível propagação do COVID-19 por meio da "telona" e da "telinha". Interessante notar que, enquanto na televisão assistem-se aos noticiários do "poder" (da mídia, do Governo, dos poderosos, ...) no celular, através das redes sociais e mundiais, recebe-se o mais variado, democrático e plúrimo informativo sobre os acontecimentos; eventualmente, entre fakes e fatos. Em meio à histeria e ao razoável e, mesmo, em meio à própria ignorância de autoridades e de pessoas em geral, iniciou-se inovadora maneira de olhar o mundo, de viver e de encarar o futuro da humanidade. Nas redes sociais, entre importantes relatos e notícias, passou-se a deparar com chistes do tipo: "estou em casa e, proibido (a) de sair à rua e ir aos bares; tive, então, que conversar com meu parceiro (a), concluindo, ... que parece ser boa pessoa!" Ao que se vê, as pessoas, incrivelmente, tiveram de desistir ou "suspender" seu frenesi existencial e pararam para conversar com os seus, até por egoísmo para a preservação da própria vida!

No primeiro momento, entretanto, a incredulidade no potencial de virulência do COVID-19 espraiou a ignorância sobre os fatos. Pessoas dispensadas de suas aulas e dos locais de trabalho deslocavam-se para as praias como se de férias estivessem, queriam, apesar de estarem em quarentena, limitar e não proibir, nos condomínios, o acesso às áreas comuns como quadras, brinquedotecas, piscinas e, até, propunham "compartilhamento" de saunas para "somente dois ou três indivíduos"; queriam levar seus filhos ao parquinho para tomar sol e "brincarem juntos", permitir festas nos salões comunitários, etc.; pessoas idosas recusavam-se a abandonar seu jogo de dominó nas praças públicas, banhistas queriam passear nas orlas marítimas de um País abençoado com praias e sol exuberantes e, assim por diante.

Em que pese a gradual conscientização popular, já, no final da primeira semana de quarentena, (de 16 a 20 de março de 2020), em diversas cidades do Brasil e, mesmo, em outras partes do Planeta iniciou-se a ocorrer algo diferente; assim, perceberam-se ruas, parques e praias vazias, e; esplendidamente, a natureza passou a cumprir seu eficiente e inexorável papel. Impressionantemente, os canais marítimos de Veneza ficaram translúcidos, o ar das grandes cidades mais 
límpido, as ruas menos sujas, e o silencio passou a propagar uma estranha paz em um Planeta que, de forma geral, desacelerou a frenética vida diária da humanidade. Agora, tudo que se queria era voltar a conversar com alguém, voltar ao parque, à praia, ao convívio social; por outro lado, para aqueles que tinham suas famílias, era especial momento de reencontro. Era a volta aos tempos "da casa da avó". Particularmente, lembramos de quando, na infância, adorávamos ir com o avô paterno a horta, ainda, como "gaúcho", no interior do Rio Grande do Sul, "trazer as vacas de leite para o estábulo", "trazer a água, em baldes, para dentro da casa", colocar lenha e cavacos perto do fogão e, há.... o fogão a lenha,... como era bom, sentarem, os primos, à beira do fogão à lenha para "mexer no fogo"... e, depois, sentar à beira da grande mesa de jantar para ouvir as "histórias dos adultos" e, depois, obviamente, não mais tarde do que às 9:00 horas da noite, dormir. Tempos bucólicos que ficaram esquecidos para a geração " $X$ " e que as gerações² "Y", " $Z$ ", índicos e etc. não conheceram.

O Planeta passa a ser outro durante estes acontecimentos do primeiro semestre de 2020. Não que já não se tivessem vivido outras catástrofes e eras Glaciais, e grandes Guerras fratricidas, e peste Negra, na Idade Média, Gripe Espanhola; enfim, sem contar com as tragédias comuns do dia a dia moderno; no trânsito das autopistas, os acidentes automobilísticos; nas grandes e pequenas cidades, a proliferação de crimes e homicídios, etc. Passou a haver, porém, agora, algo de novo, literalmente, "no ar"; um insignificante e invisível "vírus mortal" que, incubado no ser humano, mata em poucos dias com pneumonia e a chamada Síndrome da Insuficiência Respiratória Aguda (SDRA). Já se tinha passado, em 2009, pela "gripe suína" H1N1, e perdas humanas já se haviam registrado no mundo; mas, agora, em 2020, algo diferente está acontecendo, o ataque mortal do COVID-19 atua, principalmente, aniquilando idosos, porém, matando-se número menor de jovens, comprometendo-os, como hospedeiros não sintomáticos, a serem

\footnotetext{
2 Fala-se de geração Baby Boomer (de 1946-1964), geração "X" (de 1960 a 1980), geração "Y" (de 1980 a 2000), geração "W" (de 1991 a 2000), geração "Z" (de 1990 a 2010) e geração ALPHA (a partir de 2010). Sobre a propedêutica divisão das últimas gerações nascidas pós-guerra, ver Baby Boomer.
} 
solidários com aqueles, tão suscetíveis a uma terrível e solitária morte, entubados até que seus pulmões esvaiam-se em último suspiro.

Em verdade, já, há algum tempo, estamos vivenciando uma série de acontecimentos que vêm atingindo fisicamente a humanidade. Catástrofes, como tsunamis (em 26 de dezembro de 2004, terremoto de magnitude 9,1 na Escala Richter, na Indonésia, exterminou com a vida de 230.000 pessoas; em 11 de março de 2011, no Japão, 15.000 pessoas perderam suas vidas em terremoto de 9,0 na Escala Richter, etc.) grandes queimadas de florestas tropicais em 2019; além de todo o (des)equilíbrio ou (re)equilíbrio planetário em termos político-jurídicoeconômico. Foram e, estão sendo questionados, desde o início dos anos 2000, os diversos sistemas em que a humanidade está inserida. Destarte, vêm-se contestados os sistemas; ambiental (modificações intensas nos ecossistemas, falta d'água, dificuldades na produção de alimentos); geopolítico (em vista das guerras e atividades de confrontamento entre Estados e nações como as guerras e ataques de 11 de setembro de 2001 às Torres Gêmeas nos Estados Unidos da América; a difusão do terror do chamado Estado Islâmico a partir de 2003, etc.); político (mudanças radicais nas orientações partidárias nos diversos Estados do Planeta em busca da prevalência entre as ditas, progressista esquerda e a conservadora direita) e econômico (já, em evidentes mudanças a partir de 1989, com a queda do Muro de Berlim e o fim da República Socialista Soviética-URSS, em 1990, como corolário da expansão do neoliberalismo dos anos 80 (Margareth Thatcher, no Reino Unido, Helmut Kohl na Alemanha e Ronald Reagan nos Estados Unidos da América). A enumeração de fatos é meramente exemplificativa para chamar a atenção de que esses anos iniciais do Século XXI não seriam fáceis ou que, ainda, seriam precursores ou predecessores de incomparáveis anos de renovação, de inovação, de revelação, de modificação dos parâmetros de existência da vida na Terra enquanto "casa" da humanidade.

De fato, muitos já anunciavam, mesmo de forma apocalíptica, que um novo mundo viria (e, indefectivelmente, virá), cada um a seu jeito, segundo seu conhecimento, tradições religiosas, filosófico-morais e científicas. Natural pensar assim, até mesmo porque o avanço científico-tecnológico vivenciado no Século 
passado e até os dias atuais de 2020 propiciaram, ao ser humano, uma enorme capacidade de questionamento, de análise, de constatação científica e, consequentemente, de previsibilidade, de razoável domínio das condições de vida.

que nossa geração (" $X$ " - dos anos 60-70) presencia de avanços nas telecomunicações, na ciência médica, na computação, nas relações sociais, etc. é de deixar qualquer um, que tenha vivido, até então, perplexo. O que não se fez ou o que se fez e se demorou para fazer em dezenas de milhares de anos; com o acúmulo de racionalidade, tornou-se o patamar científico para o desabrochar de um mundo incrivelmente tecnológico e facilitado pelas conquistas do estudo e da pesquisa científica, como visto nos últimos cento e cinquenta anos. Trata-se da vitória da razão, uma inigualável conquista dos atuais anos que, ainda, temos o (des)prazer de testemunhar com nossos próprios olhos.

Entretanto, nem tudo nos aparece como um florido campo de girassóis (lembrando Vincent Van Gogh) já que, se por um lado, é esplêndido o desenvolvimento das tecnologias, das artes, das ciências e das letras; por outro, o avanço moral do homem é extremamente questionável. Desta forma, a celebre frase do pintor holandês "Quando um cego grita para outro cego, os dois tropeçam na mesma pedra" é incrivelmente hodierna e representativa do atual estado de avanço da nossa humanidade. Somos cegos guiando cegos já que, tendo olhos, vemos, mas não podemos enxergar o necessário papel evolutivo do homem em seu habitat natural. Tornamo-nos cegos de uma cegueira moral, espiritual, essencial quanto à real natureza humana.

A tragédia humana então se intensifica em uma sociedade doentia segundo a falta de tempo, o produtivismo, a não alteridade, o crime desenfreado, o desemprego, a fome, a destruição do meio-ambiente, a insatisfação no viver, o abandono, a desilusão e tantos males do presente Século. A vida tornou-se difícil, empobrecida, mortificante ou; ainda, para alguns, mais abastados, monótona, repetitiva e enfadonha. Tanta literatura passou-se a produzir para solucionar o grande problema do Século; qual seja, a solidão em si mesmo; a busca da autoajuda tornou-se imperiosa para tantos e, apesar de uma certa acomodação de cada um aos novos tempos, eis que, para além das predições de tantos visionários como 
Nostradamus, Júlio Werner e, mesmo, de entes moralmente emancipados como um Francisco Cândido Xavier, uma Madre Tereza de Calcutá, dentre tantos iluminados, grandes desafios foram apresentados a uma humanidade que, se tecnológica e cientificamente avançou, esqueceu seu humanismo, abandonou o seu desenvolvimento moral, negou suas faculdades transcendentais, perdeu suas capacidades e potencialidades extra sensoriais, etc.

Em meio às incertezas da existência, enfrentamos a AIDS, nos anos 80, a doença da vaca louca, em 1990, a gripe aviária, em 2005, a gripe suína, em 2009, o H1N1, em 2009, dentre outras tragédias (para não falar de sarampo, meningite, fome, etc.) e; agora, no final de 2019 (em 31 de dezembro de 2019), no prelúdio dos anos vinte do Século XXI, deparamo-nos com o chamado Corona vírus (SARS-CoV2), que causa a infecção respiratória denominada COVID-19. Nos últimos quase três meses, estudos, pesquisas, gráficos e mais gráficos demonstram o incrivel potencial de expansão do dito vírus segundo escala exponencial pelo mundo que conhecemos, de forma a que nenhum sistema de saúde, em escala mundial, tenha condições de atender ao "pico de demanda" de leitos de Centros de Tratamento Intensivo CTIs. Se, na China, a partir de Wuhan, desenvolveram-se pioneiras pesquisas, Estados europeus como Itália, Espanha, França e Alemanha, para não dizer os demais, lutam freneticamente, por assim dizer, através de seus cientistas, ainda em março de 2020, para tratarem minimamente seus nacionais que, infelizmente, não resistem às agruras da doença e vêm à óbito. Dezenas de milhares de pessoas sucumbem no mundo inteiro, faltam "kits" de testagem, não se tem uma vacina, multiplicam-se os casos de infecção. Neste senário apocalíptico, próprio dos filmes do gênero que povoam o senso coletivo, nosso amado Brasil está inserido, também sofrendo as consequencias de um mundo em que se investiu obstinada e demasiadamente na "Bolsa de valores", nas comodities, no mercado de armas e em tantas outras mercadorias que obscureceram, por exemplo, o investimento em saúde nos diversos Estados. No Brasil, desde o dia 25 de fevereiro de 2020, aponta-se a detecção do COVID-19, sendo que a primeira morte confirmada ocorreu em 16 de março de 2020. Na data de 17 de março de 2020, os números oficiais falaram de uma morte e 291 casos confirmados no Território 
brasileiro. Após o pronunciamento oficial do Ministro da Saúde, Luiz Henrique Mandetta, em 17 de março de 2020, em que aconselhou o povo brasileiro a "cuidar dos idosos" em vista de que se teria de enfrentar "em torno de vinte semanas a partir do surto epidêmico que serão estremamente duras para as famílias, para as pessoas..." os sites oficiais não pararam de atualizar os números em vista de inexorável crescimento das vítimas desse invisivel inimigo biológico. Em meio às desencontradas notícias e depoimentos nas redes sociais que davam conta de diversos casos nas CTI's no Brasil afora, já circulavam projeções de que a pandemia poderia levar a óbito milhares de vidas de brasileiros.

O inédito, agora, é que, nunca, em escala mundial ou no Território brasileiro, a sociedade civil tinha sido mobilizada tão rapidamente (ou nem tanto como se esperava) para tentar "resistir" na "guerra contra o COVID-19". Ainda que, incrivelmente, em um primeiro momento, na semana de 16 a 20 de março de 2020, pessoas tivessem "aproveitado" o fato de que não tinham que comparecer às aulas ou que haviam sido dispensadas no emprego para ficarem em quarentena em suas casas junto dos seus familiares, e tivessem ido para a "praia e bares"; a conscientização e, também, a partir de 17 de março de 2020, a proliferação de determinações de ordem pública fechando estabelecimentos comerciais, determinando prisão e multas para quem não obedecesse a quarentena e determinando hospitalização compulsória acabaram por diminuir sensivelmente a circulação de pessoas no País (passou-se a questionar a juridicidade/ constitucionalidade das normas, o "afrontar" ao "direito de ir e vir", etc). Colégios e Universidades fechados, supermercados em processo de esgotamento repentino em seus estoques, mudanças de rotinas nos lares iniciaram em março de 2020 no Brasil. As redes sociais passaram a "transbordar" de informações não alvissareiras e nos noticiários, avidamente assistidos, não se falou de outra coisa. Entre a histeria e o frio contato com uma realidade nunca enfrentada antes, ainda pesam os números alarmantes da tragédia então enfrentada por Estados como Espanha e Itália em que proliferam páginas e páginas de obituários nos jornais.

O insustentável quadro leva ao término dos estoques de máscaras cirúrgicas, álcool gel e luvas nas farmácias (com direito a agressões em 
supermercados); de outra banda, Estados como a China e os Estados Unidos da América anunciam pesquisas já, em seres humanos, para a descoberta de eventual vacina. As autoridades brasileiras pululam em seus discursos, ainda em uma rasa disputa política, que logo dá lugar a um discurso apocalíptico em relação à gravidade dos fatos (fecham-se estradas e vias de acesso aos Municípios e Estados infelizmente e, por óbvio, sem barrar o avanço letal do COVID-19). Todos questionam se o Brasil estaria pronto para debelar tantas dificuldades ${ }^{3}$. Aliás, para além de certa desconfiança de que vencer tantos desafios será demasiado difícil, passa-se a entender que a conquista de saúde e a superação dessa tragédia humanitária só ocorrerá com considerável perda de vidas humanas, em vista da experiência de outros Estados.

Da descrição do surto de Coronavírus em virtude do COVID-19 no mundo dos anos vinte do Século XXI, restam algumas assertivas a saber: a) a rapidez de expansão do contágio nunca vista antes, em escala exponencial; b) o despreparo das autoridades mundiais para lidar com o vírus em meio a Sistemas de saúde inéptos ou não devidamente aparelhados (pessoal e economicamente); c) a mobilização da sociedade civil, em escala mundial, para quarentenas; d) o debacle dos sistemas econômicos, das economias, dos pequenos e dos grandes empreendimentos em virtude da queda drástica da produção, do consumo, da circulação e da repartição da renda; e) a necessidade do Estado ou, mesmo, de algo diferente em escala político-institucional local e mundial para lidar com a novel situação que exige inovador aparato institucional; f) a necessária alteridade e visão interpessoal entre pessoas e governantes, interligados regional e globalmente, para acharem soluções conjuntas; g) a incapacidade generalizada para lidar-se com o imponderável e fatídico vírus que pôs por terra todas as certezas dos poderosos e dos fracos, ambiciosos e inconsequentes, geniais e ingênuos e; h) o potencial das tecnologias para tentar substituir ou, provavelmente não, a necessária proximidade

\footnotetext{
${ }^{3}$ As notícias nas redes sociais e as melhores estatísticas começaram a prever números assustadores para a expansão exponencial da contaminação e de mortes descrevendo-se números consideráveis a partir da primeira quinzena de abril de 2020. O futuro permitirá que esta nota seja adequadamente preenchida com mortificantes e desanimadores dados.
} 
física entre seres humanos - caracteristica tão bem elucidada por Aristóteles (o homem é um animal social).

Até aqui, desenhou-se, ainda que timidamente, a trajetória de eventos que, em verdade, para além de questionar a evolução tecnológica, científica e racional da humanidade, trouxe elementos para suscitar a modificação existencial espiritual, moral e mental do "homem universal". A partir disso, alguns questionamentos:

Estar-se-ia em pleno processo de transição planetária; de um modelo de viver egoísta e individualista para o início de um tempo em que a tomada de decisão exige o consenso de uma ágora social universal?

Seria possível imaginar o limiar de um processo de depuração social para implementação de um mundo altero? Com outros padrões político-econômicosociais?

Evidenciar-se-ia, agora, em virtude da premência dos fatos, a necessidade de avanço moral próprio de um despertar da consciência individual e coletivo, relevando-se a necessidade de explorar-se o potencial do espírito, da mente e do corpo como corolário do "desenvolvimento do homem integral"?

Estaria, a humanidade, no descortinar do Século XXI, sendo, inquestionavelmente, despertada, a exemplo da tradição bíblica em que Moisés, através de tantos fenômenos e "pragas" exaltaria a mudança moral de um povo?

Para além das assertivas religiosas, científicas e filosóficas, evidencia-se que a trajetória dos acontecimentos, inicialmente, aqui, descritos, para além de tantas outras tragédias individuais e coletivas, tem de ter um sentido, tem de ter uma utilidade. Qual então?

Se a tecnologia avançou tanto, as dificuldades presentes apontam para o (re)questionamento das relações sociais, econômicas e jurídicas nas suas facetas produtivas, consumeristas, ambientalistas, culturais, politicas, normativas etc.

Afirma-se então que, tanto podem dar-nos indícios de que, mais uma vez, após tantas experiências nefastas vividas em milênios, séculos e décadas anteriores, o homem conduz-se pela sua desastrosa ação em sociedade a impulsionar a autodestruição. De outra banda, pode estar sendo, a humanidade, indelevelmente conduzida, em uma explicação metafísica, à ação ética, moral e 
socialmente aceitável, bem como a modificar-se pela novel experiência virulenta de dor existencial. Desde já, também, afirmamos que esta crise sanitária não haverá de ser a derradeira "lição existencial" que fará o ser humano "humanizar-se"; porém, o curso de ação do homem será extremamente questionado, seja pelos inegáveis acontecimentos que haverão de ocorrer em detrimento da própria tenacidade deste em permanecer desconectado com a sua essência, seja pelas consequências de seus atos irresponsáveis no Planeta. Planta-se vento, colhem-se tempestades; neste sentido, também, consequência da atual ambição e não alteridade na civilização, só podem ser verificados os desastrosos atos que prejudicam a própria existência humana e de todos os seres vivos no Planeta. Urge então que, nós, cientistas do Direito e da Economia contribuamos pragmaticamente para uma renovação da visão de mundo.

Dois economistas heterodoxos como Joseph Schumpeter (1982;1961) e seus ensinos sobre inovação, destruição criadora e desenvolvimento e; Douglass North ${ }^{4}$, com seu discurso sobre a necessidade de mudanças a partir das Instituições e a eficiência adaptativa já têm nos feito intuir que estamos, em 2020, a viver, em escala mundial, a "autodestruição renovadora eficiente-econômico-social" $(\operatorname{ADRECOS})^{5}$. Estamos a viver a destruição criadora que "mata" pessoas físicas e jurídicas ${ }^{6}$. O interessante é que tal força levanta-se pela mão do próprio homem. Desta vez, entretanto, não se trata de medida normativa originada dos legislativos mundiais, nem do despotismo dos governos e, também, não é fruto da ultima racio judicial. Agora, os delineamentos político-econômico-sociais da humanidade são

${ }^{4}$ NORTH; DAVIS, 1971; NORTH; THOMAS, 1973; NORTH, 1978; NORTH, 1981; NORTH, 1990; NORTH, 1997; NORTH, 1993; NORTH, 1998; NORTH, 1999.

${ }^{5}$.Firmamos aqui novel expressão: autodestruição renovadora eficiente-econômico-social (ADRECOS): ação humana renovadora que, detentora de todo o ideal benfazejo próprio do homem, bem como, da mesma forma, eivada de todas as possíveis impropriedades humanas, conforme ao seu eventual estado de consciência vivificado o leva à eficiência econômico-social destruindo o status quo para a reconstrução de novel mundo dos fatos indelevelmente voltado para o inexorável progresso. A bem da verdade, o homem tem fraquejado e alternado entre um agir promissor e uma ação destruidora e autodestruidora; porém; acreditamos, sempre, dirigindo-se, a humanidade, para o inarredável sucesso de convívio harmônico entre os indivíduos de sua espécie e destes para com os demais seres vivos.

${ }^{6}$ Se não bastassem as perdas de vidas humanas e a diminuição da atividade econômica; em virtude da ausência do próprio homem nos mercados consumeristas e nas linhas de produção, inexoravelmente ocorrea estagnação de mercados e à recessão econômica. Incrivelmente, o COVID19 prova que a economia "gira" para o homem e não o homem serve a economia. 
traçados pela ação do livre arbítrio do próprio homem que criou seu "monstro destruidor invisível" - o COVID-19. Queremos crer que, conscientemente, não era intenção humana tal desiderato (como não foi em tragédias anteriores já enumeradas) mas seja, movido pelo poder, pelo desejo do lucro ou da conquista da glória (ARISTÓTELES, 1997) ou; ainda, pela busca do avanço político-econômico de Estados em detrimento de outros, conseguiu-se implementar o desastre fatal neste primeiro quartel do Século XXI, qual seja, a mortandade, em grande escala, de muitos e tantos em todo o território planetário pela ação virulenta de um inimigo comum e que não tem cores partidárias, nem econômicas, nem ideológicas. Já não se trata dos equívocos da guerra entre nações, ou do trânsito homicida nas cidades ou das políticas públicas de exclusão social que matam pela fome, mas; agora, estáse a enfrentar a pura e simples Lei de causas e efeitos da ação humana global. Um vírus que poderia ter surgido em qualquer lugar, de rios poluídos, de plantações envenenadas, de "mercados molhados", de pacientes literalmente "empilhados" em hospitais infectados com super bactérias, etc., que existem no mundo inteiro, não sendo "privilégio" de um ou outro Estado.

Se o homem foi capaz de tamanha façanha autodestrutiva, pelo menos não chegou aos estertores de uma guerra nuclear (possivelmente, influenciado, metafisicamente, pela espiritualidade que, em vistas de evitar um mal maior, permitiu que se espraiasse, no Planeta, a virulência atual que, certamente, ainda assim, é de grande custo para as famílias). Depois desta catástrofe, ainda deverão vir algumas outras, epidêmicas, climáticas, geológicas, tantas quantas forem necessárias para refrear a ação autodestrutiva do ser humano. É como se fosse um aprendizado longo e doloroso para modificar o pensamento de uma "criança teimosa" chamada "homem" que se, na infância, brincava com seus brinquedos e, eventualmente os quebrava, agora, brinca de ser gente grande, ainda, "quebrando brinquedos de adultos". Muitos irão perecer (pessoas físicas e jurídicas e, mesmo, as relações políticas como as conhecemos), será como que uma onda gigante, um tsunami 
arrasando tudo e a todos de alguma forma; entretanto, depois da catástrofe ${ }^{7}$, ressurgiremos, humanizados e depurados pela dor. Já, aí, teremos a verdadeira liberdade política, a necessária igualdade jurídica e a solidária e fraterna economia: liberdade, igualdade e fraternidade serão derradeiramente alcançadas.

Importante destacar que, em momentos de crise, surgem muitas opiniões e debates científicos e, para além da imprescindível pesquisa de vacinas em laboratórios, em outras áreas, o debate flui também, como no Direito e na Ciência Econômica. O debate científico e de alto nível sobre política jurídico-econômica e Análise Econômica do Direito (AEDI); ora pregando posições mais liberais, ora intervencionismo Keynesiano Estatal, ora medidas ortodoxas, ora heterodoxas; comprova que o maravilhoso é perceber, em tempos de crise, que a teoria científica justifica-se na urgência da prática, em todas as áreas, para que rápida $e$ pragmaticamente se alcance o bem comum. Embora sendo cedo para previsões, estamos, em verdade, no limiar de novas estruturas político-jurídico-econômicas em escala mundial. Nós, da AEDI, tendo presenciado a acumulação e o uso extremo do capital, como exemplifica-se com a economia Chinesa (que soube - devidamente ou não, nas regras do capitalismo, buscar, com grandes custos sociais e eficientismo extremo, o lucro e a hegemonia ou quase hegemonia global - sendo, hodiernamente, a segunda economia mundial); agora, também presenciamos, mais do que nunca, a necessidade do Welfare-State, a exemplo do que ocorreu em 2008, com a crise do subprime oriunda da economia dos Estados Unidos da América. Assim, como se exigiram, antes e, mesmo, agora, maciços enxertos de capitais públicos para salvar a iniciativa privada, defendem-se políticas públicas intervencionistas para eliminar as falhas de mercado - desta vez, uma falha tão devastadora - um vírus difundido a partir dos "mercados molhados"? Nem mesmo os defensores liberais de mercado ou os Estadistas mais empedernidos pelo dirigismo estatal poderiam imaginar efeitos tão nefastos pela procura desenfreada da eficiência econômica!

7 Já se disse, certamente, precisaremos passar por outras "ondas de choque", afirme-se de passagem, causadas pela nossa própria ação física, para que nos apercebamos do óbvio; a alteridade como forma de sobrevivência. Agir observando o bem estar do outro para que sobrevivamos todos nos levará ao progresso em processo infinito. 
Como cientista jurídico-econômico, cremos que, com o passar do tempo, sejam os defensores liberais ou os intervencionistas de Estado aceitarão o fato de que diplomas jurídicos desconectados com a realidade não podem persistir (decretos que intentam acabar com a inflação através de esdrúxulos tabelamentos de preços ou "congelamentos" de poupanças, cruzados bloqueados; medidas provisórias que, em nome de beneficiarem empresas em processo de endividamento, derrubam os salários dos trabalhadores, etc.). É preciso ter consciência de que tais medidas jurídico-econômicas, não embasadas no adequado empirismo, podem, por fim, difundir mais recessão econômica, condenando-se gerações inteiras a sua própria sorte. Se, por um lado, a atual crise de saúde mundial que se experimenta, consequentemente, levará a uma grande recessão econômica; é possível perceber que, em um certamente vindouro momento, a "Fênix ressurgirá das cinzas". Fisicamente, muitas almas não estarão aqui para testemunhar, mas os governos, em escala mundial, iniciarão um processo de verdadeira aproximação de povos para encontrarem soluções conjuntas com vistas a eliminar o ataque do próximo vírus; para solução da destruição ambiental do Planeta; enfim, para encontrarem adequadas políticas em vista da manutenção da vida no Planeta. Economicamente, pode ser que voltemos à "era da pedra" (evidente exagero); talvez ao escambo, ou, por fim, após passarmos pelos mais variados graus do egoísmo humano, ao ressurgimento da dita Fênix em harmônica direção da solidariedade humana.

Em termos econômicos, a Lei de ação e de reação ou de causas e de efeitos pode ser vista nas curvas de oferta e demanda; destarte, ao implementarem-se medidas que, exemplificativamente, diminuem salários do funcionalismo (redistribuição de renda via Estado) e da sociedade civil (redistribuição de renda entre empresas e famílias) tem-se recíprocos efeitos na economia. A curva de oferta, com a diminuição dos custos, salários e tributos, desloca-se para a direita; por outro lado, a curva de demanda, desloca-se para a esquerda diminuindo o consumo e a arrecadação dos tributos diretos como os inerentes ao consumo. A única consequência (que deve ser empiricamente observada) será que o Ponto de equilíbrio estará em um patamar mais baixo do que o inicial. Não há mágica e a 
condução das políticas econômicas deve ser responsável para que se avaliem os custos e os benefícios na tomada de decisão. Já se tem aludido ao tema ao defender-se o Princípio da Eficiência Econômico-Social -PEES ${ }^{8}$ em vista de uma ação político-econômica que considere os reflexos sociais e o bem estar para o maior número de todos os envolvidos e suscetíveis aos reflexos da decisão políticoeconômico-jurídica. Não se pode, assim, perpetuar decisões que façam prevalecer o interesse egoísta e espúrio de poucos em detrimentos de muitos, e mesmo do Estado, em busca de inexorável ajuste de caixa; dos empresários em busca de lucros, não raras vezes, questionável do ponto de vista ético; de trabalhadores não afinados com as necessárias ações de aumento da efetividade ou busca da eficiência de sua força de trabalho; ou de uma sociedade civil, lato sensu, descompromissada com os esforços alheios (de trabalhadores e empresários).

O momento faz urgir medidas equilibradas, mormente, de parte do Estado na condução e exemplo para a sociedade civil que não pode manter-se alienada e derrotada. Tem-se que reerguer a Fênix econômica, em que todos têm de reerguer a vida; porém, não para voltar ao status quo, mas para fazer surgir uma economia solidária, progressista, inclusora e socialmente eficiente; ou, ainda, tem-se que se reorganizar a política universalmente compatível com a coexistência mútua em escala global, em vista de optar-se por políticas públicas que levem ao derradeiro desenvolvimento de todos

A razão não pode aceitar que estejamos, aqui, por simples obra do acaso. A maravilhosa trajetória do Universo, tão bem racionalizado pela física quântica, tão aprimoradamente estudado por um Albert Einstein e tantos outros magníficos cientistas; assim como, o engendramento dos reinos mineral, vegetal e animal não poderiam deixar de afirmar e reafirmar a expertise de um Charles Darwin e seu evolucionismo; para não apontar em direção ao derradeiro momento de mudança moral do homem. Reconhece-se que não se está, aqui, a tratar de um momentâneo processo que assolará o mundo no ano de 2020 e nem que o COVID-19 será o derradeiro marco nessa mudança de ordem espiritual, moral e emocional; mas os

${ }^{8}$ Ver in GONÇALVES; STELZER, 2014 e GONÇALVES; STELZER, 2012. 
acontecimentos vivificados desde o final do Século passado e início deste Século XX apontam para um esplendoroso renascer da humanidade para o que muitos apontam como "Era de aquário" - fim de um período e/ou ciclo Planetário e início de outro. Sem entrar em discussões filosóficas, mas elucidando que os fatos são graves e exigem mudanças na perspectiva de como encaramos o mundo atual (egoísta, poluído, carente de meios econômicos, injusto e desequilibrado, inclusive do ponto de vista da distribuição da riqueza e da implementação da justiça, em meio a um sistema político caótico), necessário é evidenciar a urgência de mudança na forma de como nos relacionamos e de como organizamo-nos político-socialinstitucionalmente.

Deveras importante, é constatar que já há algum tempo, Francisco Cândido Xavier, médium espírita brasileiro renomado, em nome do espírito de Emanuel (XAVIER, 2010, p.97) (Padre Manoel da Nóbrega) alertou para o fato de que o homem seria auxiliado pelo mundo espiritual se fosse capaz de se autopreservar durante cinquenta anos após 20 de julho de 1969, data em que Neil Armstrong e Buzz Aldrin alunissaram o módulo lunar Eagle. Assim, por cinquenta anos, mesmo passando pela chamada Guerra Fria entre Ocidente e Oriente, até dezembro de 2019, fomos capazes de evitar a hecatombe nuclear; entretanto, já a partir de início de janeiro de 2020, autoridades mundiais passaram a se desafiar em cima de seus arsenais nucleares incomensuravelmente destrutivos. Donald Trump, nos EUA; Kim Jong-Um, na Coréia do Norte e Hassan Rouhani, presidente do Irã, iniciaram ações protagonizando discursos de ameaça atômica reciprocas em aumento da escalada armamentista nuclear que, inevitavelmente poderia destruir nossa humanidade como a conhecemos.

Destarte, para os materialistas, a acertada política voltada para a alimentação de massas enormes de pessoas na China, nos anos 60-70, acabou sendo sabotada pela ação de uma insurgente e irresponsável indústria de manipulação de animais silvestres (até mesmo, muitas vezes ilegal ou informal), propiciando o surgimento de exóticos costumes alimentícios que, na verdade, atentariam para saciar diminuta categoria de consumidores com poder aquisitivo econômico para tal. Tal indústria alimentícia teria proliferado, em "mercados 
molhados", como o de Wuhan, na Província de Hubei, China. Com a comercialização de animais silvestres dispostos uns sobre os outros, amontoados dentro de gaiolas dispostas umas sobre as outras em franca proliferação de virulências, defendem, os mais xenófobos, que poderiam terem sido infectados humanos originando-se o implacável contágio do COVID-199.

Da mesma forma, ainda para os materialistas, inexplicavelmente, de uma hora para a outra, a agenda dos diversos Governos mundiais voltou-se para uma causa comum, apregoando-se a união das nações para a ação em vista de evidente "guerra ao inimigo comum": a virulência do COVID-19.

De outra forma, dentro de visão filosófico-espiritual (e, aqui, defendemo-nos de inevitável acusação de estarmos distante do empirismo científico tão necessário e, inclusive, seguido por nós, que nos ocupamos do estudo do Direito e da Economia em uma Universidade Federal brasileira) defendemos que a "fé raciocinada" nos pode levar a duas conclusões a saber: a um, o COVID-19 trata de fenômeno natural que, aleatória ou propositalmente surgiu e segue seu curso natural de devastação física e; a dois, trata-se de um elemento fisicamente materializado (ainda que, invisível vírus) inserido no convívio terreno para (re) ajuste físico e moral da humanidade; necessário, estratégico e oportuno que, por desígnio de uma natureza não aleatória e sim sujeita à especial ordenação (Ordem Natural de causas e efeitos) vem para modificar as relações humanas impedindo a hecatombe nuclear final.

Se por um lado, o surgimento e o desenvolvimento de uma "moderna praga", ao estilo da epopeia descrita no velho Testamento Bíblico ${ }^{10}$, em que Moisés libertou o povo hebreu do jugo dos egípcios; lembra a ação do "anjo da morte" eliminando os primogênitos (agora são eliminados os idosos); por outro, fica claro que a fatalidade ocasionada pelo CODIVIRS-19 pode ser uma "abençoada intervenção metafisica espiritual" para a diminuição ou alento de tantas dores para a humanidade; ainda

9 Neste sentido, variadas são as pesquisas do Dr. Peter J. Li. Verin https://www.google.com.br/search?sxsrf=ALeKk02NvdEGUUJa4Db5fmCD2HKsxBcwrQ\%3A1584810 891072\&ei=i0t2XsGEBJeu5OUP9KSS4As\&q=peter+j+li\&oq=peter+J+li\&gs_l=psy-

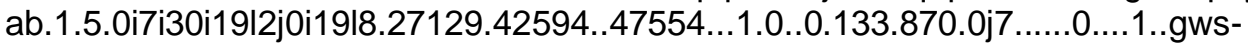
wiz......35i39j0j0i67j0i10i19j0i8i7i30i19j0i13i30i19j0i13i10i30i19j0i30i19.8kfn6yhl2xg ${ }^{10}$ Ver BÍBLIA SAGRADA, 2020. 
que com altíssimo "custo de transação individual" para usar o linguajar da nossa sempre estudada Análise Econômica do Direito; ou, mesmo, com o ceifar inexorável da vida de tantos irmãos.

$\mathrm{Na}$ primeira hipótese, tem-se visão materialista que tergiversa sobre a aleatoriedade, tanto da eventual causalidade, como dos imprevisíveis efeitos (ainda que inúmeras estatísticas sejam tentadas; a dinâmica da virulência não é possível de previsibilidade). Neste caso, perscrutam-se, tão apenas os ditames de causa e efeito: surge um vírus que, pelas leis físicas - contato humano, espraia-se e contamina matando, até que eventual vacina surja ou que a própria natureza se encarregue de terminar com seu mortal ciclo.

A segunda hipótese, nos parece mais alvissareira. Haveria, então, uma Ordem físico-moral-ético-espiritual na natureza que motivaria a atual virulência do COVID-19. Assim, o surgimento do dito vírus é fruto de uma série de contingencias jurídico-político-econômicas e, também, fruto de um estado de evolução física, moral e ética do homem que reflete seu estado moral e espiritual, como essência do seu ser que guia sua mente e, por consequência, seus atos. O homem, então, egoísta, procura saciar seus desejos mundanos, como a fome, o seu orgulho, o desejo de poder, de dinheiro, de glória (lembremos novamente Aristóteles) e gera para si problema maior: a dor da morte por Síndrome da Insuficiência Respiratória Aguda (SDRA).

Observa-se, porém, que ocorrem outros fenômenos inusitados e curiosamente interessantes na condução dos acontecimentos político-econômicoinstitucionais a partir do COVID-19.

De fato, é inegável se constate que: a) a corrida armamentista nuclear e a iminência de um conflito nuclear mundial foram bruscamente interrompidas entre as grandes potencias detentoras de tal tecnologia como Irã e os EUA; ainda que, em fins de 2019, ninguém pudesse acreditar que fosse possível tal desiderato ${ }^{11}$; b) as

11 Assim, a espiritualidade estaria, agora, em escala global, atuando sobre a humanidade para inspirar, em todos os seres humanos, a necessária e benfazeja alteridade; bem como, refrear os nefastos impulsos autodestrutivos. Cumpre-se, assim, o vaticínio de que, se a humanidade não se autodestruísse nos cinquenta anos pós chegada do homem na lua, em 1969, a Terra entraria em 
normas e disciplinamentos jurídicos passaram a ser criados em consenso assombroso e rapidez, inclusive, através de experiencias inéditas como o uso das tecnologias para viabilizar votações legislativas, vencendo-se as idiossincrasias pessoais dos legisladores; c) os conflitos de competência jurídico-administrativa entre autoridades diversas, no Planeta, do Poder Executivo, mostraram-se impertinentes e inconcebíveis ante a gravidade do problema; d) a tomada de decisões judiciais pelo mundo terreno; com base nos vetustos códigos e costumes, distanciaram-se da realidade, agora, perplexa, mesmo sob o arauto dos rábulas e da indefectível certeza daqueles que, antes, entendiam serem capazes de, em virtude de uma sentença ou deliberação administrativa, por exemplo, conseguir um leito de Centros de tratamento Intensivo - CTls para alguém; e) a natureza provou sua capacidade de auto regeneração; f) as pessoas voltaram-se para seus lares e para o convívio junto aos seus, valorizando coisas do "paraíso perdido" questionando suas prioridades e valores e; g) clarificou-se que a economia deve ser inteligentemente ordenada, dirigida com parcimônia e ética no uso dos recursos sempre estando a serviço do homem enquanto ser altero e incluso em uma humanidade que deve prosseguir seu curso no Planeta como um todo e não como forma institucionalizada de perpetuar excedentes para poucos em detrimentos de tantos. As "pragas, acompanhadas da morte", por assim dizer, não escolhem entre ricos e pobres.

Partindo-se da premissa de que o homem, até então, havia sido incapaz de modificar o estado de coisas catastróficas que lhe circundavam em sua medíocre, repetitiva e insatisfeita vida em busca de uma felicidade inalcançável, questiona-se, pois, se haveria, então, uma intervenção extraterrena (já que o homem, terráqueo, provou-se incapaz de mudar o estado de coisas que o levaria à destruição) que teria sido capaz de, em 2 meses e meio, modificar tanto e tantos no Planeta Terra?

Teria havido uma "ajudinha" para que não nos explodíssemos em uma Guerra Nuclear, não acabássemos com a biodiversidade e o meio-ambiente, não fizéssemos proliferar o desamor, a não alteridade, o assassinato cruel, a fome, o 
desespero da angustia terrena segundo mortificação nas dores e misérias existenciais de cada indivíduo?

Portanto, partindo-se do princípio de que nada é por acaso e tudo tem sua causalidade, é notório perceber que algo diferente está acontecendo em escala mundial. O Planeta Terra, nossa Casa, está em transformação, de um local de expiações para um local de regeneração de pessoas. Fomos criados para sermos felizes e não para sofrer. Se consciente ou inconscientemente já falhamos e fizemos mal ao outro; pela Lei de causa e efeito, certamente; fomos, antes, e estamos, agora, novamente, sendo instados a corrigir nossos erros de alguma forma; de outra parte, cremos que, daqui para frente, mesmo que com a perda de inúmeras e preciosas vidas físicas ${ }^{12}$ haveremos de reestruturar um "novo mundo" pelo simples fato da tomada de consciência individual em escala planetária.

Particularmente, entendemos que tal mudança Planetária não seria aleatória e sim fruto de muitos esforços de encarnados e desencarnados, de viventes físicos e viventes em espirito que interagem para fortalecer nossos potenciais mentais para um mundo melhor.

Portanto, partindo do princípio de que não há aleatoriedade na ação do homem que implementa uma economia moderna altamente tecnológica e eficiente; bem como, da premissa de que, em algum ponto de nossa trajetória evolutiva(possivelmente, nos últimos cento e cinquenta anos, dedicados à nossa evolução tecnológica), perdemos a necessária sensibilidade para com o outro; sofremos pela falta de felicidade, agora, mais evidente, em função da ação do COVID-19 e lutamos, desesperadamente, para a busca de uma solução física para um problema de atitude psíquica. Queremos nos curar do COVID-19, para; sem nenhuma mudança no interior de nossa mente e coração, sem nenhum esforço de cambio no processo econômico (produtivo e consumerista) alcançar o "éden perdido".

${ }^{12}$ Estima-se que a Peste Negra tenha ceifado, na Eurásia, entre 75 e 200 milhões de pessoas entre 1343 e 1353. A Gripe Espanhola, a sua vez, matou de janeiro de 1918 a dezembro de 1920, cerca de 50.000 .000 de pessoas. 
Desafortunadamente, ainda não nos demos conta da necessidade do inexorável salto quântico que haverá de ser dado para que se alcance essa felicidade que, antes de estar no outro, está em nós mesmos na medida em que percebamos a necessidade de agir refletindo sobre a consequência de nossos próprios atos em escala mundial. Dessa forma, o Planeta fisicamente vai se autorregenerar e, nós todos, não mais indiferentes uns aos outros, haveremos de colher, em sociedade, não os desgostos de uma tragédia individual (como a atual em que somos obrigados a nos refugiar em nossas casas, na vã tentativa de postergar o contágio virulento do COVID-19) que, certamente, de alguma forma, todos nós sofremos em maior ou menor grau; mas os abençoados frutos de um Planeta feliz, transmutado pela ação altera, solidária, benfazeja para com todos e tudo.

Para tanto, ainda no campo das Ciências Econômico-Jurídicas, deveremos fazer da Universidade e, em especial, das diversas disciplinas, repositórios repletos de conhecimentos entremeados de sã ética tendo como missão precípua, acolher os interessados no estudo filosófico, científico e cultural, mormente, destacando a compreensão da arte de viver e a superação das dores e misérias existenciais pela sublimação própria do desenvolvimento intelectual e emocional. O estudo, seja em qual for a área abordada, inevitavelmente, levará à compreensão e ao conhecimento.A sua vez, a compreensão levará ao outro - alteridade - e à aceitação, de forma que, alcançadas ambas as virtudes, por fim ou consequência, verificar-se-á a utilização do conhecimento com amor: sabedoria.

Portanto, a Universidade (como, de fato, todos os locais de estudo) é uma Escola de Aprender a Amar, nas diversas nuanças deste belo sentimento: o amor de amigos nos bancos escolares, de aprendizes e orientadores, de estudantes ávidos do crescimento integral conforme meta do amor universal e indiferentemente atribuído ao próximo. Eis uma grande meta: a alteridade com o despertar da consciência para a arte de contemplação do belo: a felicidade.

Por fim, lembre-se de que, em verdadeira harmonia de interesses, tem-se a vontade geral manifesta, em cada indivíduo, como um ato puro do entendimento que raciocina no silêncio das paixões. Destarte, a felicidade só poderá ser alcançada se 
ouvirmos escutando o outro, se enxergarmos, vendo o outro, se agirmos, pensando na felicidade do outro. Inquestionável, então, que haveremos de desenvolver e instrumentalizar todo o manancial de ferramentas físicas, mentais, psíquicas, metafisicas e espirituais para que se alcance o grande desiderato, qual seja, a vida em comunhão; a vida feliz.

Alcançado o dito estado de felicidade; já,estarão, o Brasil e a Comunidade Internacional de Países, vivenciando a necessária transição Planetária. Esperamos, sem ter que passar, novamente, pelas diversas instancias da dor, tal qual, a desafiante provação de um COVID-19 para viabilizar a benfazeja colheita futura. Haveremos, agora, de aprender que temos de mudar nosso padrão vibratório, temos de nos associar em objetivos mais sublimes, temos que controlar nossa ambição, temos que abrir nossos corações alteros para a renovação do Planeta. E tudo isso sem medo de sermos felizes. Parece-nos, mesmo, que não se trata de uma opção e sim de condição inexorável da Lei de progresso; ainda que tantos teimem em continuar em velhos padrões existenciais.

Uma última palavra tem que ser expressa (e não em nota de rodapé) para que sejam registradas, para os amados leitores, as circunstancias em que se escreve, até para que se enfatize o angustiante momento. Particularmente, escrevemos em necessário confinamento fisico em nosso apartamento próximo à Universidade Federal de Santa Catarina; obviamente, circundados por 42 praias, atualmente, desertas em Florianópolis, Santa Catarina; ainda, acompanhado de nossa amada e irriquieta família; ladeado por nossos vizinhos no condomínio (sessenta famílias, também em quarentena); organizando nossos mantimentos para que permaneçamos por meses em isolamento. Por sorte, para alem de puro acesso à tecnologia que ainda nos é permitido, recebemos informações do exterior pelas tecnologias que, se nos informam, também nos desafiam a superar a dor por tantos que estão partindo sem haver ou pouco havendo a fazer para evitar a inexorável trajédia. Outrossim, é tão alvissareiro contatar, pelo celular, amigos, redes, contatos, parentes, grupos, etc. Coisas tão simples que se tornaram tão essenciais.

Portanto, ainda escrevendo, não podemos realmente prever o que ocorrerá nos próximos meses ou quando, inevitavelmente tivermos que ir ao supermercado 
para comprar víveres. Sabemos que se alguem ficar doente no nosso convivio, teremos, fatalmente, que expor o grupo familiar ao vírus COVID-19. Sabemos que aproximadamente, cerca de $80 \%$ dos casos de infecção não terão maiores problemas para recuperação ou serão assintomáticos; entendemosque os outros $18 \%$ dos casos, eventualmente necessitarão de maiores cuidados na recuperação; mas, também estamos cientes de que aproximadamente $2 \%$ dos casos terão que ser devidamente internados ou acompanhados possivelmente sendo necessaria a internação e a entubação nos respiradores pulmonares. É bom que se registre que, hodiernamente, o acompanhamento nos hospitais e , especialmente, nos Centros de tratamento Intensivos - CTIs é proibido e, mesmo, velórios, em paises como a Itália, já são impossíveis de serem acompanhados. Trata-se de um momento surreal.

Paradoxalmente, ainda que sem certezas, inclusive, para com nós mesmos e nossa saúde; tal situação nos deixa, como cientista do Direito e Economia, extremamente independentes para escrever sobre uma fenomenologia essencialmente importante e intensamente desejosos de que essa missiva vos encontrem bem, no pleno gozo de suas vidas maravilhosas, que merecem a maior das dádivas a saber: a felicidade.

\section{CONSIDERAÇÕES FINAIS}

O COVID-19 vem como mais um instrumento de "reorganização" da humanidade, ainda que o custo de vidas seja tão alto do ponto de vista existencial. O ceifar da morte ainda nos deixa perplexos; porém, do ponto de vista da essência humana, grandes aprendizados podem ser introjetados em nossa experiência de vida. Somos seres em evolução, em eterno desenvolvimento, somos seres feitos para a felicidade, somos irmanados em nossa constituição física, somos vetores de felicidade em plena evolução para o bem geral da humanidade. Portanto, problemas tão sensíveis como uma virulência em escala mundial exigem imediata resposta de uma humanidade que não pode mais aceitar o isolacionismo doentio e egoístico da tomada de decisão que desconsidera o outro. Temos que arrumar nossa "casa" 
(Planeta Terra); temos que conviver com nosso irmão (o próximo, que pode ter o COVID-19), temos que evoluir para além das conquistas tecnológicas e materiais (desenvolver nossas capacidades de lidar com o fluido universal, de emancipar nossas mentes, de elevar nossa vibração fisico-espiritual) e, por fim, temos que aprender a lidar com nossos potenciais psiquicos, mentais, espirituais e evolutivos que transcendem a materialidade do nosso corpo (e que estão tão inexplorados).

Evidente, então, que necessitamos de um "salto quantico" para melhor viver, para bem viver, para sermos felizes. Precisamos tornar nossas Ciências, Econômica e jurídicas, adequadas para emancipação das pessoas, para torna-las felizes, para que atuem, em sociedade, com intuito de diminuirem as dores e misérias existenciais. Porque não difundir a felicidade a partir da Academia? Basta, em realidade, que voltemos nossos esforços para a difusão do conhecimento com sabedoria. Isso é amor.

Merecemos a felicidade. E se nós não a alcançarmos, fisicamente, nesta vida, cremos que nossos filhos, netos e bisnetos terão esse direito e oportunidade. Assim, desejamos que eles não tenham que enfrentar um COVID-19, porque thes deixaremos, certamente, após intenso sacrificio, um mundo melhor.

\section{REFERÊNCIAS}

ARISTÓTELES. Ética a Nicômacos. Tradução Mário da Gama Kury. 3. ed. Brasília, D. F.: Universidade de Brasília. C 1985, 1992 e ARISTÓTELES. Política. Tradução Mário da Gama Kury. 3. ed. Brasília, D. F.: Universidade de Brasília, 1997.

BÍBLIA SAGRADA. São Paulo: Vozes. 2020.

BRASIL. Ministério da Saúde. Disponível em: <https://d24am.com/saude/ministerioda-saude-deixa-de-lado-atualizacao-de-dados-sobre-coronavirus/>. Acesso em: 18 mar. 2020.

FRANCO, Divaldo Pereira. Divaldo fala sobre o Coronavírus. Disponível em $<$ https://www.youtube.com/watch?v=MWGnVls2OCQ>. Acesso em 20.03.2020. 
GERAÇÕES W, X, Y, Z, ALFA - DOS BABY BOMMERS AOS MILLENNIALS. $<$ https://www.spaltron.net/somos-indigo-e-cristais/geracoes-w-x-y-e-z-alfa-dos-baby$\mathrm{html} />$. Acesso em 20/03/2020.

GONÇALVES, Everton das Neves; STELZER, Joana. Princípio da Eficiência Econômico-Social no Direito Brasileiro: a tomada de decisão normativo-judicial. Revista Sequência. Florianópolis (SC), v. 35, n. 68, 261-290, jun. 2014.Disponível em $<$ https://periodicos.ufsc.br/index.php/sequencia/article/view/21777055.2013v35n68p261>. Acesso em: 20 mar. 2020.

GONÇALVES, Everton das Neves; STELZER, Joana. Eficiência e Direito: pecado ou virtude, uma incursão pela Análise Econômica do Direito. In: Revista Jurídica UNICURITIBA. Curitiba, PR: Unicuritiba. Revista Eletrônica, v. 1, n. 28. 2012. P. 77122. ISSN 0103-3506. Disponível em <http://revista.unicuritiba.edu.br/ index.php/RevJur/article/view/412/317>. Acesso em: 20 mar. 2020.

LI, Peter J. Disponível em: <https://www.google.com.br/ search?sxsrf=ALeKk02 NvdEGUUJa 4Db5fmCD2HKsxBcwrQ\%3A1584810891072 \&ei=i0t2XsGEBJeu5OU P9KSS4As\&q=peter+j+li\&oq=peter+J+li\&gs_l=psy-ab.1.5.0i7i30i19|2j0i19|8.27129. 42594..47554..1 1.0..0.133.870.0j7..........1...gws-wiz.......35i39j0j0i67j0i10i19j0i8i 7i30i19j0i13i30i19j0i13i10i30i19j0i30i19.8kfn6yhl2xg >. Acesso em: 20 mar. 2020.

NORTH, D. e DAVIS, L. Institutional Change and American Economic Growth. Cambridge University Press, Cambridge, 1971.

; THOMAS, Robert P. The Rise of the Western World: A New Economic History. Cambridge University Press, Cambridge, 1973.

Structure and performance: the task of economic history. In: Journal of Economic Literature, 16, 1978.

Structure and Change in Economic History. Norton, New York, 1981.

Institutions, Institutional Change and Economic performance. $\overline{\text { Cambridge University Press, Cambridge, } 1990 .}$

Institutions, transaction costs, and the rise of merchant empires, in The Political Economy of Merchant Empires, State Power and World Trade 13501750, James D. Tracy (ed.), Cambridge University Press, Cambridge, 1997, (1ed. 1991).

Autobiography, in The Bank of Sweden Prize in Economic Sciences in Memory of Alfred Nobel, 1993. 
- Epilogue: economic performance through time, in Empirical Studies in Institutional Change, Alston L., Eggertsson T., North D., (eds.), Cambridge University Press, Cambridge, 1998 (1ed. 1996).

Understanding the process of Economic Change, in lea Occasional Paper, London, 1999.

SCHUMPETER, J. A. Capitalism, socialism and democracy. New York: Harper and Brothers, 1961.

A Teoria do Desenvolvimento Econômico: uma investigação sobre lucro, capital, crédito, juro e o ciclo econômico. Rio de Janeiro: Nova Cultural, 1982.

XAVIER, Francisco Candido e GOMES, Saulo (org.). Pinga-Fogo com Chico Xavier. Catanduva, SP: Intervidas, 2010, p. 97. 